\title{
Mass spectrometry-based iTRAQ analysis of serum markers in patients with pancreatic cancer
}

\author{
KAI JIA $^{1}$, XIA ZHAO ${ }^{2}$ and XUEYI DANG ${ }^{1}$ \\ ${ }^{1}$ Department of General Surgery, Shanxi Cancer Hospital, Taiyuan, Shanxi 030013; ${ }^{2}$ Department of \\ Occupational Health and Poisoning Control, Shanxi Province Centers for Disease Control and Prevention, \\ Taiyuan, Shanxi 030001, P.R. China
}

Received August 22, 2018; Accepted May 14, 2019

DOI: 10.3892/ol.2020.11491

\begin{abstract}
Early biomarkers for pancreatic cancer (PC) detection are required in order to improve patient outcomes. The present study aimed to identify serum biomarkers for PC diagnosis using proteomics, unveil the underlying pathological mechanisms and provide reliable data for the early diagnosis of PC. Isobaric tags for relative and absolute quantification and two-dimensional-liquid chromatography-tandem mass spectometry were used to compare serum samples from patients with PC and healthy individuals. Mascot and Scaffold were used for raw data processing, and Panther for gene ontology (GO) analysis. Igenuity ${ }^{\circledR}$ Pathway Analysis (IPA) was utilized to assess canonical pathways and protein-protein interactions. In total, 76 differentially expressed proteins were identified. The candidate protein DNA repair protein 50 (RAD50) was elevated in patients with PC compared with healthy individuals. In addition, transforming growth factor- $\beta 1$ (TGF- $\beta 1$ ) and apoptotic protease activating factor 1 (APAF-1) were downregulated in PC. GO analysis revealed that the extracellular matrix was increased in PC, as well as receptor function and enzyme regulation; additionally, reduced nucleic acid binding transcription factor activity was observed. IPA analysis demonstrated that the significantly altered canonic pathways were liver $\mathrm{X}$ receptor/retinoid $\mathrm{X}$ receptor (RXR) activation, the production of nitric oxide and reactive oxygen species in macrophages, the coagulation system, acute phase response signaling and lipopolysaccharide/interleukin-1 mediated inhibition of RXR function. To conclude, RAD50, TGF- $\beta 1$ and APAF1 are candidate biomarkers for the diagnosis of early
\end{abstract}

Correspondence to: Professor Xueyi Dang, Department of General Surgery, Shanxi Cancer Hospital, 3 Workers' New Street, Taiyuan, Shanxi 030013, P.R. China

E-mail:wcwkhy@163.com

Abbreviations: PC, pancreatic cancer; iTRAQ, isobaric tags for relative and absolute quantification; GO, gene ontology

Key words: pancreatic cancer, biomarker, isobaric tags for relative and absolute quantification analysis, mass spectrometry, serum
PC. The results from the present study could help identify future therapeutic drugs for PC.

\section{Introduction}

Pancreatic cancer (PC) is an aggressive malignant tumor with a low survival rate; the 5-year survival rate of this malignancy is $<8 \%$, making it the third major cause of cancer-associated mortality in the USA (1). It has been predicted that PC will become the second leading cause of cancer-associated mortality after lung carcinoma by 2030 (2). Such high mortality is caused by delayed diagnosis due to a lack of early diagnostic tools. Indeed, the early diagnosis of PC serves a vital role in disease prognosis and the design of personalized therapy. Due to the lack of overt symptoms at the early stage of PC, missed diagnosis rates range between 39 and 70\% (3). Patients with advanced stages of PC demonstrate a more severe physical condition compared with those diagnosed in the early stage (4). In addition, certain tumor biomarkers play important roles in the early diagnosis, therapy and monitoring of $\mathrm{PC}$, such as carbohydrate antigen (CA)19-9, CA242, vascular endothelial growth factor (VEGF), CA724 and CA125. However, although the levels of the aforementioned tumor biomarkers are elevated in certain individuals with PC, this is not the case for all, and so they have low levels of sensitivity and specificity (5). More strikingly, CA19-9 is a biomarker approved by the US Food and Drug Administration for PC diagnosis, with a sensitivity of 70-81\%; however, it fails to detect PC in the early stages of disease (6). Therefore, new tumor biomarkers that serve significant roles in the early diagnosis of PC are urgently needed.

Currently, proteomics is considered a powerful tool for accurate monitoring and quantification of protein expression changes (7). Indeed, several proteomic technologies have been widely used for the identification of biomarkers, including two-dimensional electrophoresis, stable isotope labeling with amino acid in cell culture, two-dimension difference gel electrophoresis and isobaric tags for relative and absolute quantification (iTRAQ) (8). Previously, iTRAQ-based analysis has been used to quantitatively assess the changes in protein abundance in various biological samples, with high sensitivity and reproducibility (9). For instance, this approach has been successfully used to identify diagnostic markers of gastric and lung cancer $(8,9)$. 
The iTRAQ technology is increasingly used in the field of cancer research; plasma or serum protein analysis via quantitative proteomics of patients with PC reveals cancer-associated proteins and polypeptides in comparison with specimens from non-diseased and chronic pancreatitis controls (10). Thus, the present study aims to assess serum proteins in patients with PC and healthy controls, providing a basis for screening serum biomarkers, which would be used in the early diagnosis of PC.

\section{Materials and methods}

Subjects. A total of 15 freshly collected serum specimens were obtained from patients (mean age, $51.70 \pm 3.10$ years; all male) diagnosed with PC (without hypertension or diabetes) between January 2013 and January 2014 at Shanxi Provincial Cancer Hospital (Taiyuan, China). The samples were obtained prior to treatment (Fig. 1). The diagnosis criteria were based on the Guidelines for Diagnosis and Treatment of Pancreatic Cancer (2014 Edition) from Group of Pancreatic Surgery, Branch of Surgery, Chinese Medical Association (11). The American Joint Committee on Cancer (AJCC) Tumor-Node-Metastasis (TNM) staging is the most widely used cancer staging system worldwide. According to the AJCC 8th edition staging system for patients with PC, 7 patients had been diagnosed as stage IIB, and 8 patients had been diagnosed as stage III (12) (Table I). The tumor status of 15 patients with PC are shown in Table II. During the same period, 10 healthy control subjects undergoing physical examinations at Shanxi Provincial Cancer Hospital (mean age, 56.40 \pm 2.42 years; all male) were enrolled. The present study was approved by The Ethics Committee of Shanxi Provincial Cancer Hospital (approval no. 201732), and written informed consent was obtained from each participant.

Serum collection and preservation. Blood samples were collected in the morning before the patients had eaten, placed at $4^{\circ} \mathrm{C}$ for $1.5 \mathrm{~h}$, and centrifuged at $3,000 \mathrm{x} \mathrm{g}$ for $10 \mathrm{~min}$ at $4^{\circ} \mathrm{C}$. The resulting supernatant (serum) was collected and stored at $-80^{\circ} \mathrm{C}$.

Depletion of highly and lowly abundant proteins. The serum samples from 15 patients and 10 healthy controls collected at baseline were immuno-affinity depleted of highly abundant proteins using a Multiple Affinity Removal Column Human 14 (4.6x50 mm; Agilent), according to the manufacturer's protocol. Lowly abundant proteins were collected on a high-performance liquid chromatography (HPLC) system (1260 Infinity II LC System; Agilent) using dilution, stripping and neutralization buffers provided, according to the manufacturer's protocol. The detailed conditions were: Column, Agilent HC-C18 (4.6x150 mm, $5 \mu \mathrm{m})$; mobile phase, methanol/water 20:80 (v/v) containing 0.05 M potassium dihydrogen phosphate (pH 3.5); detection wavelength, $238 \mathrm{~nm}$; flow rate, $1.0 \mathrm{ml} / \mathrm{min}$; column temperature, $35^{\circ} \mathrm{C}$; injection volume, $20 \mu \mathrm{l}$. To $200 \mu \mathrm{l}$ plasma, $600 \mu 110 \%$ perchloric acid was added; after mixing, the sample was centrifuged at $16,000 \times \mathrm{g}$ for $10 \mathrm{~min}$ on a GL-20G-II high-speed desktop refrigerated centrifuge (Flying Pigeon; Shanghai Anting Scientific Instrument Factory, Shanghai). Following this, $20 \mu \mathrm{l}$ of the resulting supernatant was used for quantitative analysis.
Protein quantification and SDS-PAGE electrophoresis. The serum original samples of patients with pancreatic cancer and healthy controls were analyzed by SDS-PAGE. Serum protein levels were determined using a Bradford assay kit (Beyotime Institute of Biotechnology). The depletion efficiency of each approach was evaluated by SDS-PAGE. A Coomassie Blue Stain kit PH0351 (Feijing Scientific Research Reagent Store) was used containing $100 \mathrm{ml}$ Coomassie Blue stain and $500 \mathrm{ml}$ Coomassie Blue decoloring solution. Coomassie blue staining was performed at $23^{\circ} \mathrm{C}$ for $2-4 \mathrm{~h}$ followed by decolorizing at $23^{\circ} \mathrm{C}$ for $4-8 \mathrm{~h}$. The type of gel was SDS-PAGE gels. No two-dimensional separation was used. Then, equal amounts $(15 \mu \mathrm{g})$ of total protein were separated by $12 \%$ SDS-PAGE electrophoresis.

Peptide extraction and iTRAQ labeling. In total, $200 \mu \mathrm{g}$ of highly abundant protein depleted serum was denatured with $200 \mu \mathrm{l}$ dithiothreitol $(20 \mathrm{mmol} / \mathrm{l})$ at $37^{\circ} \mathrm{C}$ for $1 \mathrm{~h}$, and alkylated with iodoacetamide $(50 \mathrm{mmol} / \mathrm{l})$ at room temperature for $45 \mathrm{~min}$. Urea $(8 \mathrm{~mol} / \mathrm{l})$ was used for elution, and ammonium bicarbonate $(25 \mathrm{mmol} / \mathrm{l})$ for washing. Finally, trypsin was used overnight to digest the serum proteins at $37^{\circ} \mathrm{C}$, and the reactions were terminated by addition of formic acid at a final concentration of $1 \%$. Next, iTRAQ labeling was performed for peptides from healthy controls and PC samples using an iTRAQ reagent 8-plex kit (Applied Biosystems; Thermo Fisher Scientific, Inc.), according to the manufacturer's protocol. Peptides were desalted, dried and labeled with different isobaric tags for $2 \mathrm{~h}$ at $25^{\circ} \mathrm{C}$. Peptides enriched in serum samples from healthy controls and patients with PC were labeled with 116 and 117 tags, respectively. Finally, the labeled peptides were dried under vacuum and stored at $-80^{\circ} \mathrm{C}$.

Separation of iTRAQ-labeled peptides under high $\mathrm{pH}$ reversed phase $(R P)$ conditions. Digestion and iTRAQ labeled serum samples were reconstituted in $400 \mu \mathrm{l}$ of $20 \mathrm{~mm}$ ammonium formate $/ 2 \%$ acetonitrile ( $\mathrm{pH} \mathrm{10).} \mathrm{Following} \mathrm{this,}$ the samples were loaded on an RP C18 capillary column (3, $4.6 \mu \mathrm{m} \times 250 \mathrm{~mm}$; Shimadzu Corporation) and fractionated on an Agilent 1100 series HPLC instrument by basic RP chromatography at a flow rate of $1.0 \mathrm{ml} / \mathrm{min}$. The mobile phase consisted of $90 \%$ acetonitrile $(\mathrm{pH} \mathrm{10)}$, used with a gradient of 5 to $30 \%$ solvent B (formic acid), for 0-60 min. Fractions were collected every $1 \mathrm{~min}$ for a total of 60 fractions; early and late fractions were pooled, resulting in a total of 30 fractions. The pooled samples were reconstituted in $0.1 \%$ formic acid for liquid chromatography-tandem mass spectrometry (LC-MS/MS) analysis.

LC-MS/MS analysis. Peptides in each fraction were separated on an RP C18 capillary column $(3,75 \mu \mathrm{mx} 100 \mathrm{~mm})$ and eluted using a linear gradient of 5 to $30 \%$ solvent B1 $(0.1 \% \mathrm{v} / \mathrm{v})$ formic acid in acetonitrile for $40 \mathrm{~min}$, at a flow rate of $300 \mathrm{nl} / \mathrm{min}$ ). MS data were acquired by the shotgun proteomics method (LTQ-Orbitrap mass spectrometer; Sanofi S.A.); in each cycle, a full scan was acquired at a resolution of 30,000 dpl with a mass range of $380-1,600 \mathrm{~m} / \mathrm{z}$. Up to 10 of the most intense precursor ions with charge range of +2 to +4 were selected with an isolation window of $2 \mathrm{Da}$, and subsequently fragmented by higher-energy collisional dissociation with a normalized 
Flowchart of patients inclusion

\section{0 patients diagnosed with pancreatic cancer}

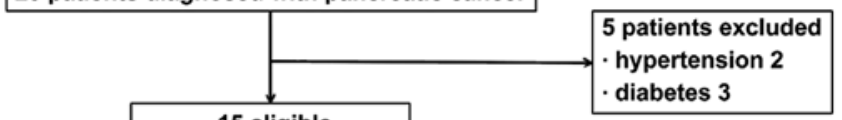

Figure 1. Flow chart presenting the inclusion criteria for patients within the present study.

collision energy of $40 \%$. The MS/MS scans were acquired at a resolution of 7,500 dpl. Precursor ions were dynamically excluded from reselection for $60 \mathrm{sec}$.

Database analysis. Raw data from the mass spectrometer were analyzed by the Mascot (version 2.3.02; http://www. matrixscience.com/) and Scaffold (version 4.4.3; Proteome Software, Inc.) programs. The search database was Swiss-Prot (uniprot.org) (human species). Tyrosine served as a variable modifier protein. The search parameters were: Trypsin allowed $\mathrm{P}$ enzyme specificity, with up to two missing cleavages; precursor ion mass tolerance, $\pm 10 \mathrm{ppm}$; fragment ion mass tolerance, $0.05 \mathrm{Da}$; fixed modification, carbamidomethylation and no variable modification. The identified proteins were quantified according to the iTRAQ of the specific polypeptide. Differential proteins in serum proteome: Differential multiple $>1.5, \mathrm{P}<0.05$.

Gene ontology (GO) and Igenuity ${ }^{\circledR}$ Pathway Analysis (IPA) analyses of differentially expressed proteins. Differentially expressed proteins (ratio $>1.5$ or $<0.5 ; \mathrm{P}<0.05$ ) were imported into the Panther database (pantherdb.org/) and matched with the human genome data. Following this, the proteins were classified into molecular function, biological process and cellular component according to gene ontology (GO). Canonical pathway, upstream regulation and protein-protein interaction analyses were performed by the IPA software (Ingenuity Systems; Qiagen, Inc.).

Statistical analysis. Data are presented as mean \pm standard deviation. SPSS 19.0 software (SPSS; IBM Corp.) was used to analyze the results. Student's t-test was applied to compare mean values between the two groups. $\mathrm{P}<0.05$ was considered to indicate a statistically significant difference.

\section{Results}

Characteristics of patients with PC. As presented in Table III, serum CA19-9, CA242, CA724, CA50 and VEGF levels in patients with $\mathrm{PC}$ were significantly increased compared with the values of healthy controls. In addition, these diagnostic factors were higher than normal levels, except VEGF.

Qualitative and quantitative analyses of serum proteins following immuno-affinity depletion of highly abundant proteins. Serum samples from patients with PC and control patients were immuno-affinity depleted of the 14 most abundant proteins using Multiple Affinity Removal Column Human
Table I. Number of patients with pancreatic cancer at each stage of the 8th edition of the American Joint Committee on Cancer staging system (12) for pancreatic cancer.

\begin{tabular}{lc}
\hline Variables & Number of patients \\
\hline Tumor depth & \\
T1 & 4 \\
T2 & 7 \\
T3 & 4 \\
Lymph node metastasis & \\
N1 & 7 \\
N2 & 8 \\
Distant metastasis & \\
M0 & 15 \\
Tumor stage & \\
IIB & 7 \\
III & 8 \\
\hline
\end{tabular}

$\mathrm{N}$, node; $\mathrm{M}$, metastasis.

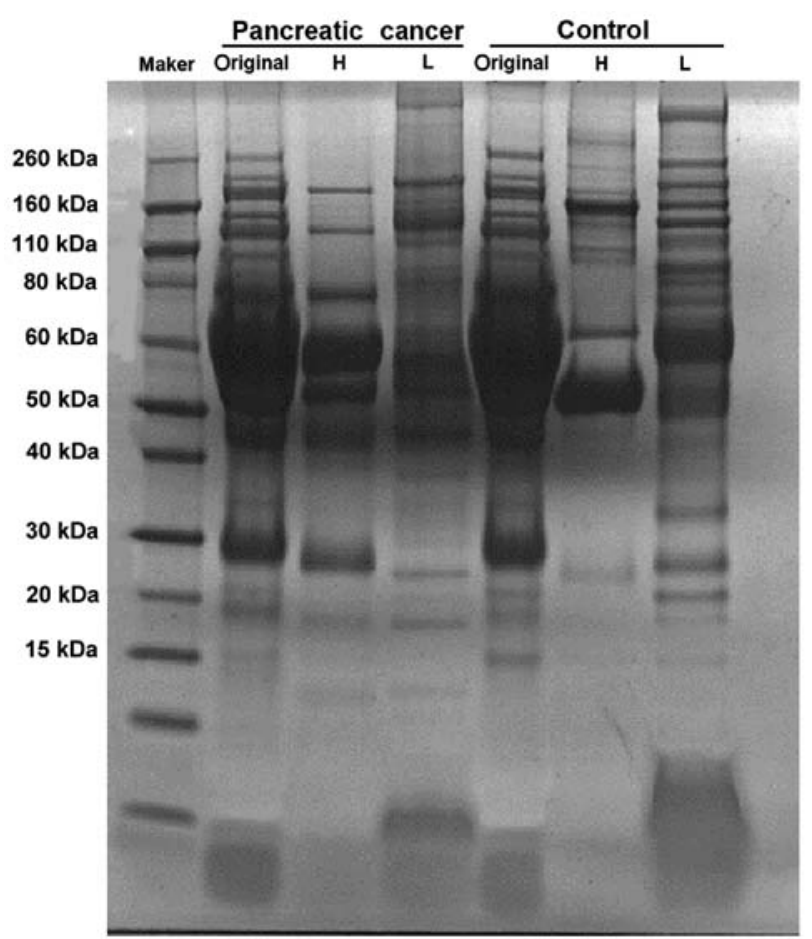

Figure 2. SDS-PAGE analysis of the serum original sample of patients with pancreatic cancer and healthy controls. Original, original serum; L, no high abundance proteins in serum; $\mathrm{H}$, high abundance proteins in serum.

14, and SDS-PAGE was performed to assess various serum samples in the two patient groups. As presented in Fig. 2, low abundance proteins demonstrated improved separation and exhibited higher concentrations. In addition, an increased number of low abundance proteins was observed; however, the albumin band disappeared. In the serum proteome, 251,479 spectra were obtained. Proteomics revealed 531 proteins, of which 442 were quantifiable. 
Table II. Tumor status of 15 patients with pancreatic cancer included in the present study.

\begin{tabular}{|c|c|c|c|c|c|c|c|c|c|}
\hline $\begin{array}{l}\text { Patient } \\
\text { no. }\end{array}$ & Sex & $\begin{array}{l}\text { Tumor } \\
\text { size, cm }\end{array}$ & $\begin{array}{l}\text { Tumor } \\
\text { site }\end{array}$ & $\begin{array}{c}\text { Degree of } \\
\text { differentiation }\end{array}$ & $\begin{array}{c}\text { Lymph node } \\
\text { Metastasis numbers }\end{array}$ & $\mathrm{T}$ & $\mathrm{N}$ & M & Stages \\
\hline 1 & Male & $3 \times 2.5 \times 2.5$ & Head of pancreas & Moderately & 3 & 2 & 1 & 0 & IIB \\
\hline 2 & Male & $1.8 \times 1.8$ & Tail of pancreas & Moderately & 1 & 1 & 1 & 0 & IIB \\
\hline 3 & Male & $3 \times 2 \times 0.5$ & Tail of pancreas & Moderately/poorly & 2 & 2 & 1 & 0 & IIB \\
\hline 4 & Male & $1.8 \times 1.8$ & Head of pancreas & Moderately & 2 & 1 & 1 & 0 & IIB \\
\hline 5 & Male & $2.5 \times 2.5 \times 2$ & Head of pancreas & Moderately & 3 & 2 & 1 & 0 & IIB \\
\hline 6 & Male & $1.5 \times 1.5$ & Head of pancreas & Moderately & 1 & 1 & 1 & 0 & IIB \\
\hline 7 & Male & $2 \times 2 \times 1.5$ & Body of pancreas & Moderately & 2 & 1 & 1 & 0 & IIB \\
\hline 8 & Male & $3 \times 3 \times 3$ & Body of pancreas & Highly/moderately & 5 & 2 & 2 & 0 & III \\
\hline 9 & Male & $3 \times 3 \times 3$ & Head of pancreas & Moderately & 4 & 2 & 2 & 0 & III \\
\hline 10 & Male & $3 \times 2.5 \times 2.5$ & Head of pancreas & Moderately/poorly & 6 & 2 & 2 & 0 & III \\
\hline 11 & Male & $5 \times 3.7 \times 3.5$ & Head of pancreas & Moderately & 8 & 3 & 2 & 0 & III \\
\hline 12 & Male & $4 \times 3 \times 3$ & Head of pancreas & Moderately & 4 & 2 & 2 & 0 & III \\
\hline 13 & Male & $4 \times 3.5 \times 3.5$ & Body of pancreas & Moderately & 5 & 2 & 2 & 0 & III \\
\hline 14 & Male & $5 \times 3 \times 3$ & Head of pancreas & Poorly & 9 & 3 & 2 & 0 & III \\
\hline 15 & Male & $5 \times 4 \times 4$ & Head of pancreas & Highly & 8 & 3 & 2 & 0 & III \\
\hline
\end{tabular}

T, Tumor; N, Node; M, Metastasis.

Table III. Clinical data and carbohydrate antigen levels in healthy controls (male) and patients with pancreatic cancer (male) $($ mean $\pm \mathrm{SD})$

\begin{tabular}{|c|c|c|c|c|}
\hline Variable & $\begin{array}{l}\text { Healthy control } \\
\text { group }(n=10)\end{array}$ & $\begin{array}{l}\text { Patients with pancreatic } \\
\text { cancer group }(n=15)\end{array}$ & $\begin{array}{l}\text { Reference } \\
\text { values }\end{array}$ & P-value \\
\hline Age, years & $51.70 \pm 3.10$ & $56.40 \pm 2.42$ & - & - \\
\hline Complications & None & None & - & - \\
\hline CA19-9 & $5.05 \pm 2.01 \mathrm{U} / \mathrm{ml}$ & $251.3 \pm 63.87 \mathrm{U} / \mathrm{ml}$ & $<20 \mathrm{U} / \mathrm{ml}$ & $\mathrm{P}<0.01$ \\
\hline CA242 & $2.12 \pm 0.71 \mathrm{U} / \mathrm{ml}$ & $28.76 \pm 13.82 \mathrm{U} / \mathrm{ml}$ & $<12 \mathrm{U} / \mathrm{ml}$ & $\mathrm{P}<0.01$ \\
\hline CA724 & $4.31 \pm 1.29 \mathrm{U} / \mathrm{ml}$ & $12.76 \pm 7.62 \mathrm{U} / \mathrm{ml}$ & $<10 \mathrm{U} / \mathrm{ml}$ & $\mathrm{P}<0.05$ \\
\hline CA50 & $5.48 \pm 1.46 \mathrm{U} / \mathrm{ml}$ & $176.0 \pm 60.71 \mathrm{U} / \mathrm{ml}$ & $<20 \mathrm{U} / \mathrm{ml}$ & $\mathrm{P}<0.05$ \\
\hline VEGF & $185.0 \pm 60.36 \mathrm{pg} / \mathrm{ml}$ & $365.0 \pm 39.67 \mathrm{pg} / \mathrm{ml}$ & $62-707 \mathrm{pg} / \mathrm{ml}$ & $\mathrm{P}<0.05$ \\
\hline Total, $\mathrm{n}$ & 10 & 15 & - & - \\
\hline Age, years & $51.70 \pm 3.10$ & $56.40 \pm 2.42$ & - & - \\
\hline Complications & None & None & - & - \\
\hline
\end{tabular}

CA, carbohydrate protein; VEGF, vascular endothelial growth factor.

GO analysis. Based on the aforementioned 442 quantifiable proteins, more than two peptide segments were identified by Mascot and Scaffold. There were 76 differentially expressed proteins in samples from patients with $\mathrm{PC}$ compared with control specimens (Table IV). Among them, 70 proteins were downregulated, with 24 demonstrating a coordination ratio of 0.4 or more. Meanwhile, six proteins were upregulated by $2-3$ fold. To comprehensively assess the biological significance of the 76 differentially expressed proteins, analysis was performed by the Panther gene classification system, which includes biology processes, cellular components, molecular functions and protein classes. Compared with the normal serum proteome database (pantherdb.org/chart/summary/pantherChart.jsp?filterLevel=1\&
chartType $=1 \&$ list Type $=1 \&$ type $=5 \&$ species $=$ Homo $\% 20$ sapiens ), proteins associated with the extracellular matrix, receptor activity and enzyme regulator activity were upregulated in patients with $\mathrm{PC}$, and those involved in the extracellular matrix accounted for $6.8 \%$ of all proteins (Fig. 3). However, proteins involved in nucleic acid binding transcription factor activity and metabolic processes were significantly downregulated.

Pathways identified by IPA. A bioinformatics analysis of the identified differentially expressed proteins was performed using the IPA software. As presented in Fig. 4, certain pathways were significantly altered. Proteins in the coagulation system $\left(\mathrm{P}=4.97\right.$; ratio, $\left.1.43 \times 10^{-1}\right)$ and lipopolysaccharide/interleukin-1 
Table IV. Analysis of the 76 differentially expressed proteins identified in the serum of patients with pancreatic cancer and healthy controls.

A, Upregulated proteins

\begin{tabular}{llc}
\hline Protein & ID (Swiss-Prot) & Change fold \\
\hline Cluster of transmembrane protease serine 13 & Q9BYE2 & 3 \\
Triose-phosphate isomerase & P60174 & 2.5555556 \\
Complement factor H-related protein 2 & P36980 & 2.5 \\
Lysozyme C & P61626 & 2.2222222 \\
DNA repair protein RAD50 & Q92878 & 2.2 \\
WD repeat-containing protein 67 & Q96DN5 & 2 \\
\hline
\end{tabular}

B, Downregulated proteins

\begin{tabular}{|c|c|c|}
\hline Protein & ID (Swiss-Prot) & Change fold \\
\hline Cadherin-related family member 2 & Q9BYE9 & 0.4545455 \\
\hline Apolipoprotein C-I & P02654 & 0.4545455 \\
\hline Cluster of membrane primary amine oxidase & Q16853 & 0.4545455 \\
\hline A-kinase anchor protein 13 & Q12802 & 0.4444444 \\
\hline Cluster of $\mathrm{Ig} \kappa$ chain $\mathrm{V}$-III region WOL & P01623 & 0.4166667 \\
\hline Titin & Q8WZ42 & 0.4 \\
\hline Ig $\kappa$ chain $V$-I region EU & P01598 & 0.4 \\
\hline Polymeric immunoglobulin receptor & P01833 & 0.4 \\
\hline Mast/stem cell growth factor receptor kit & P10721 & 0.4 \\
\hline Collagen $\alpha-1(\mathrm{I})$ chain & $\mathrm{P} 02452$ & 0.4 \\
\hline Roundabout homolog 4 & Q8WZ75 & 0.4 \\
\hline G-protein coupled receptor 126 & Q86SQ4 & 0.4 \\
\hline Protein RRP5 homolog & Q14690 & 0.4 \\
\hline Plasminogen activator inhibitor 1 & P05121 & 0.4 \\
\hline 4F2 cell-surface antigen heavy chain & P08195 & 0.4 \\
\hline Plexin-B1 & $\mathrm{O} 43157$ & 0.4 \\
\hline Sushi, nidogen and EGF-like domain-containing protein 1 & Q8TER0 & 0.4 \\
\hline Multiple epidermal growth factor-like domains protein 8 & Q7Z7M0 & 0.4 \\
\hline Androgen receptor & P10275 & 0.4 \\
\hline TRAF3-interacting protein 1 & Q8TDR0 & 0.4 \\
\hline NACHT, LRR and PYD domains-containing protein 6 & P59044 & 0.4 \\
\hline Ankyrin repeat domain-containing protein 30A & Q9BXX3 & 0.4 \\
\hline Collagen $\alpha-1(\mathrm{XVI})$ chain & Q07092 & 0.4 \\
\hline Protein QN1 homolog & Q5TB80 & 0.4 \\
\hline$\alpha$-amylase 1 & P04745 & 0.375 \\
\hline Ig heavy chain V-III region GAL & P01781 & 0.3636364 \\
\hline A disintegrin and metalloproteinase with thrombospondin motifs 13 & Q76LX8 & 0.3636364 \\
\hline Proteasome subunit $\beta$ type- 4 & P28070 & 0.3636364 \\
\hline Endoglin & P17813 & 0.3636364 \\
\hline Leukocyte elastase inhibitor & P30740 & 0.3636364 \\
\hline Sodium channel protein type 8 subunit $\alpha$ & Q9UQD0 & 0.3636364 \\
\hline Desmoglein-2 & Q14126 & 0.3333333 \\
\hline Msx2-interacting protein & Q96T58 & 0.3 \\
\hline Unconventional myosin-XV & Q9UKN7 & 0.3 \\
\hline Serum amyloid A-4 protein & P35542 & 0.3 \\
\hline Apolipoprotein C-IV & P55056 & 0.3 \\
\hline Golgi-associated plant pathogenesis-related protein 1 & Q9H4G4 & 0.3 \\
\hline Vascular endothelial growth factor receptor 3 & P35916 & 0.3 \\
\hline Kinesin-like protein KIF20B & Q96Q89 & 0.3 \\
\hline
\end{tabular}


Table IV. Continued.

B, Downregulated proteins

Centromere protein $\mathrm{F}$

Ig heavy chain V-III region JON

Leukemia inhibitory factor receptor

Cingulin-like protein 1

$\mathrm{G}$ protein-coupled receptor kinase 5

Plasma serine protease inhibitor

Plexin-D1

Lactotransferrin

Pericentrin

Dystonin

Serine-protein kinase ATM

Pyruvate dehydrogenase (lipoamide) kinase isozyme 2, mitochondrial

Serine/arginine repetitive matrix protein 1

Apolipoprotein C-III

Hornerin

Protein shroom2

Transmembrane protein 74

Serine/threonine-protein kinase WNK4

RING finger protein 214

Midasin

Dynein heavy chain 11, axonemal

Regulatory-associated protein of mTOR

Zinc finger ZZ-type and EF-hand domain-containing protein 1

Poly (ADP-ribose) polymerase 1

Probable ATP-dependent RNA helicase DDX46

Peregrin

Semaphorin-4B

Nesprin-1

Canalicular multispecific organic anion transporter 1

Apoptotic protease-activating factor 1

Sodium/hydrogen exchanger 2

\begin{tabular}{|c|c|}
\hline P49454 & 0.3 \\
\hline P01780 & 0.3 \\
\hline P42702 & 0.3 \\
\hline Q0VF96 & 0.3 \\
\hline P34947 & 0.3 \\
\hline P05154 & 0.2727273 \\
\hline Q9Y4D7 & 0.2727273 \\
\hline P02788 & 0.25 \\
\hline O95613 & 0.25 \\
\hline Q03001 & 0.25 \\
\hline Q13315 & 0.2307692 \\
\hline Q15119 & 0.2307692 \\
\hline Q8IYB3 & 0.2222222 \\
\hline P02656 & 0.2 \\
\hline Q86YZ3 & 0.2 \\
\hline Q13796 & 0.2 \\
\hline Q96NL1 & 0.2 \\
\hline Q96J92 & 0.2 \\
\hline Q8ND24 & 0.1818182 \\
\hline Q9NU22 & 0.1666667 \\
\hline Q96DT5 & 0.1666667 \\
\hline Q8N122 & 0.1538462 \\
\hline O43149 & 0.1538462 \\
\hline P09874 & 0.125 \\
\hline Q7L014 & 0.125 \\
\hline P55201 & 0.125 \\
\hline Q9NPR2 & 0.117647 \\
\hline Q8NF91 & 0.1 \\
\hline Q92887 & 0.1 \\
\hline O14727 & 0.1 \\
\hline Q9UBY0 & 0.1 \\
\hline
\end{tabular}
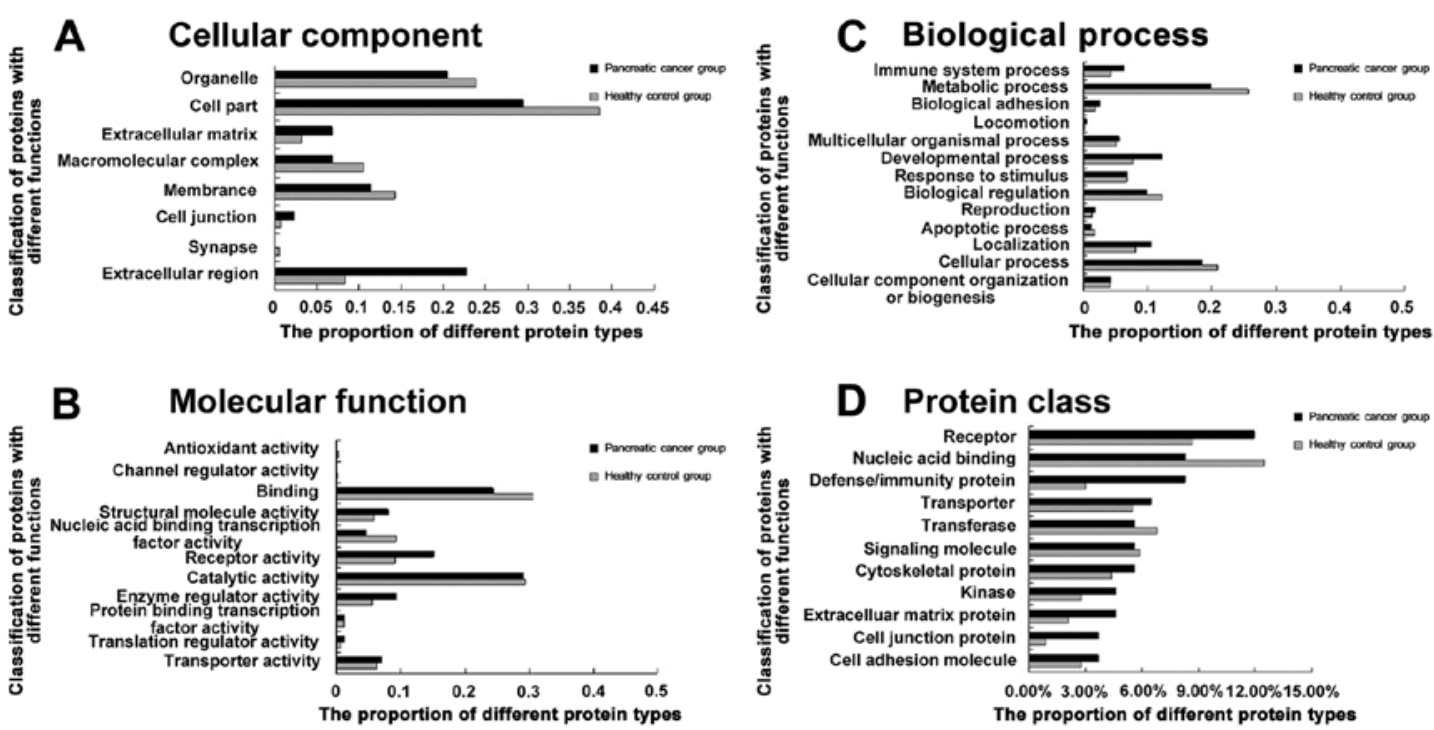

Figure 3. Gene Ontology analysis of differentially expressed proteins in immuno-affinity depleted serum. (A) Cellular components. (B) Molecular functions. (C) Biological process. (D) Protein class. The y-axis displays different functions, while the x-axis presents the proportion of different protein types. Black, pancreatic cancer group; gray, healthy control group. 


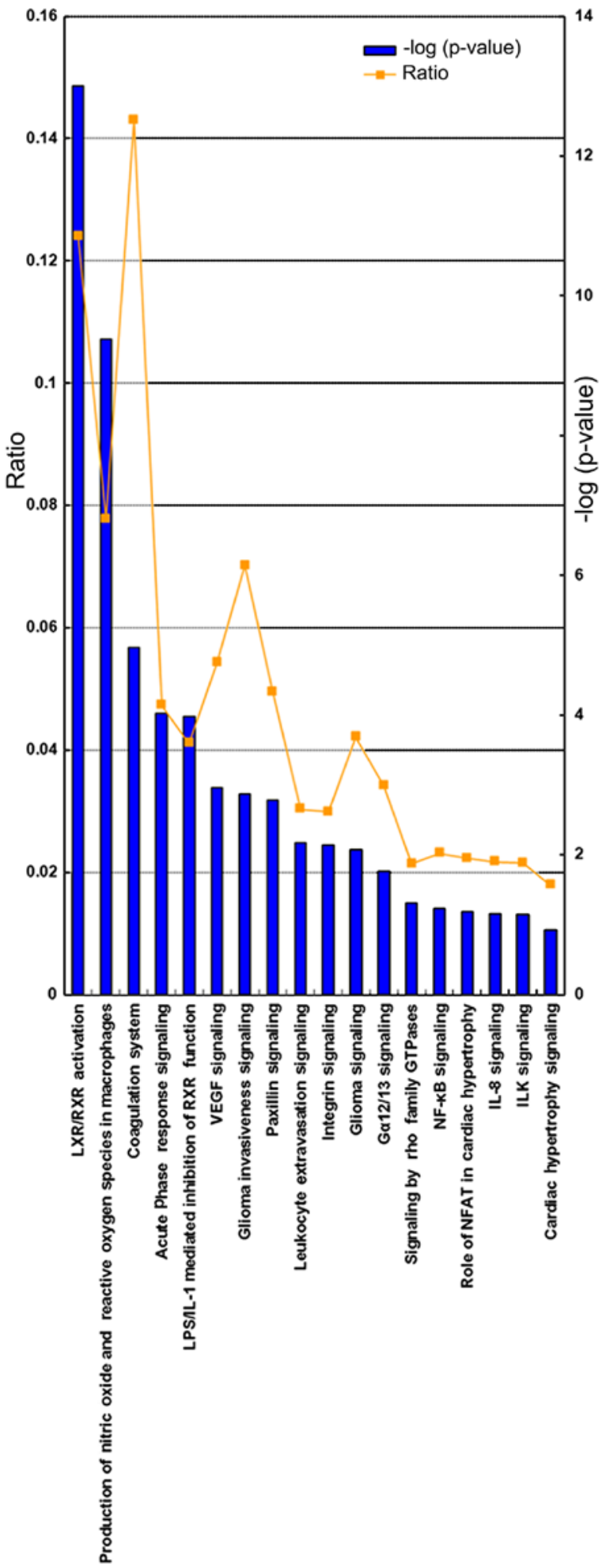

Figure 4. Analysis of biological pathways of the differentially expressed proteins in patients with pancreatic cancer and healthy controls using the Ingenuity Pathway Analysis software. $-\log (\mathrm{P}$-value) reflects the significance between proteins and the pathway. The higher the score, the higher the degree of significance. LXR, liver X receptor; RXR, retinoid X receptor; LPS, lipopolysaccharide; IL, interleukin; VEGF, vascular endothelial growth factor; NF-кB, nuclear factor $\kappa \mathrm{B}$; NFAT, nuclear factor of activated T-cells; ILK, integrin linked kinase.

mediated inhibition of retinoid $\mathrm{X}$ receptor (RXR) function $\left(\mathrm{P}=3.98\right.$; ratio, $\left.4.11 \times 10^{-2}\right)$ were significantly upregulated. In comparison, liver $\mathrm{X}$ receptor/RXR activation $(\mathrm{P}=13.00$; ratio, $\left.1.24 \times 10^{-1}\right)$, production of nitric oxide and reactive oxygen species in macrophages $\left(\mathrm{P}=9.38\right.$; ratio, $\left.7.78 \times 10^{-2}\right)$, paxillin signaling $\left(\mathrm{P}=2.78\right.$; ratio, $\left.4.95 \times 10^{-2}\right)$, and integrin signaling $\left(\mathrm{P}=2.14\right.$; ratio, $\left.2.99 \times 10^{-2}\right)$ were significantly downregulated. In addition, some differentially expressed proteins were involved in cell survival, molecular translocation, viral infection and lipid efflux, revealing decreased levels. A protein interaction network analysis also revealed that certain associated proteins were upregulated or downregulated (Fig. 5).

\section{Discussion}

CA199 is a tumor-associated antigen (13). It is present in the majority of healthy individuals. Not all individuals are able to produce similar levels of CA19-9; the levels are closely associated with physiological characteristics and genetic status (13). The physiological level of CA19-9 varies from individual to individual due to their different genotypes. In the serum of those with Lewis (Le) antigen Le-a (+) and Le-b (-) genotypes, CA19-9 is maintained at a certain level (14). The serum CA19-9 level of Le-a (-), Le-b (+) genotype was relatively low. CA19-9 could not be detected in the serum of individuals with Le-a (-), Le-b (-) genotype. In individuals who are negative for Lewis antigen, CA19-9 was not significantly elevated despite the PC tumor being large. Despite CA19-9 being a PC-specific antigen, its specificity and sensitivity to the PC tumor are low, which makes it difficult to use CA19-9 as a biomarker in screening for the early diagnosis of PC, although it is a common method (14). CA19-9 has been detected in various other types of cancer, including pancreatic (84\%), gallbladder (69\%), colorectal (39\%) and ovarian (35\%) cancer (15). Pancreatitis, hepatitis, biliary inflammation and obstructive diseases have been reported as the most common benign diseases exhibiting elevated levels of CA19-9 (15). The diagnostic sensitivity of CA19-9 for PC decreased when the critical value of CA19-9 increased and when the specificity level increased. When the critical value of CA19-9 reached $100 \mathrm{ku} / \mathrm{l}$, the sensitivity and specificity were 68 and $98 \%$, respectively (14). Even though CA19-9 is considered a good diagnostic marker for PC, it should not be used for screening of the early stages of PC, as the levels of CA19-9 are rarely elevated in this stage (14). Even when the PC lesions have been detected using CT, but the tumor size was $<3 \mathrm{~cm}$, only $50 \%$ of the patients had elevated CA19-9 (14). The most important role that CA19-9 serves in PC is to evaluate the recurrence of PC and the efficacy of radiotherapy and chemotherapy following surgery via assessing the changes in the levels of CA19-9. Despite the level of CA19-9 in patients with PC being increased $>10$ times in the present study, it could not be used as a direct indicator for the diagnosis of PC.

The present study assessed serum proteins in patients with PC and healthy controls and identified a total of 531 proteins using iTRAQ technology. Among them, 442 were quantitatively analyzed. Several differentially expressed proteins were observed in subjects with PC in comparison with healthy controls, including APAF-1, RAD50 and TGF- $\beta 1$. GO and IPA analyses demonstrated that the differentially expressed proteins mainly participated in the extracellular matrix component, receptor function, enzyme regulation, nucleic acid binding transcription factor activity and metabolic-associated 


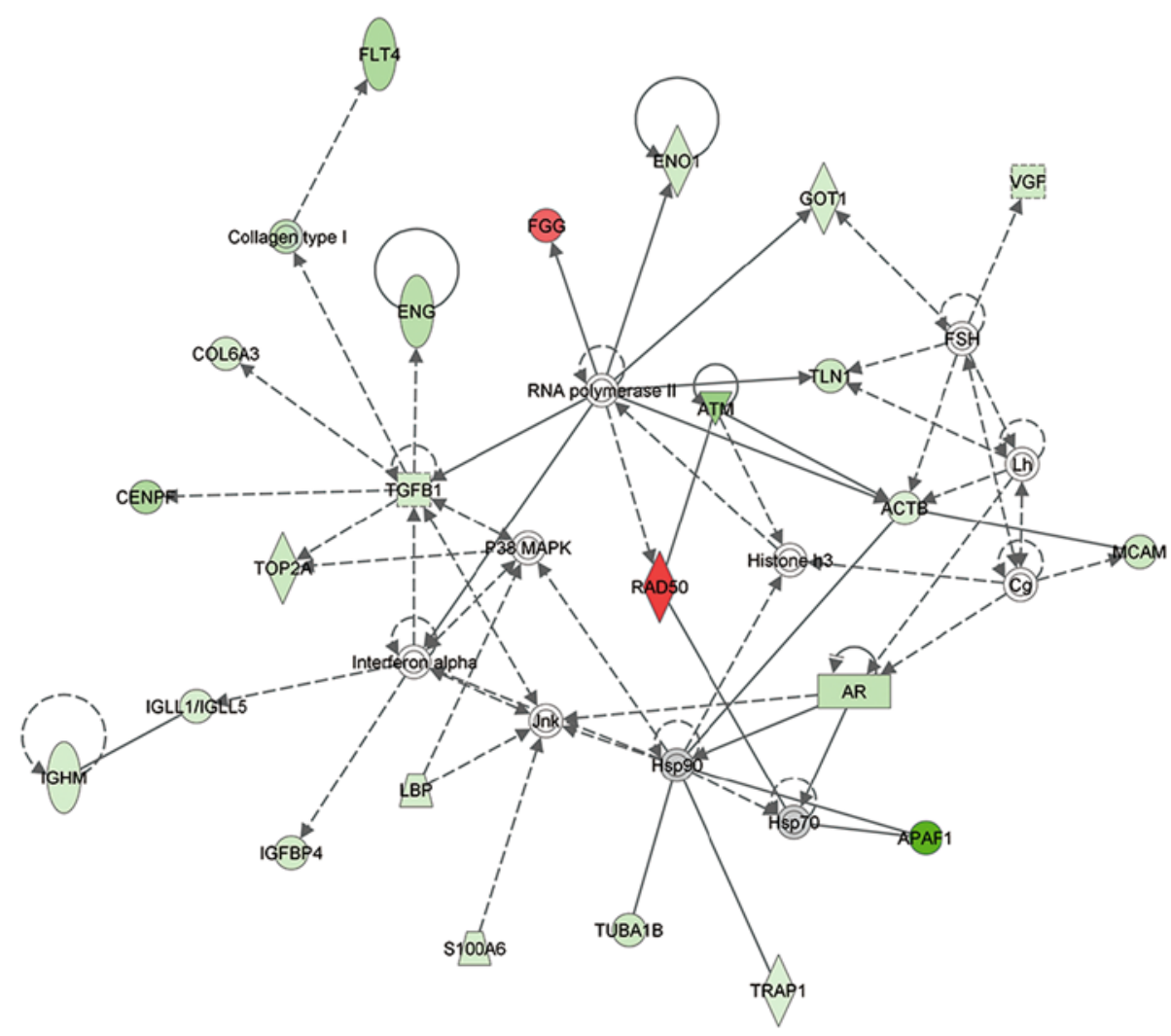

Figure 5. Interaction network of differentially expressed proteins between patients with pancreatic cancer and healthy controls, assessed by the Ingenuity Pathway Analysis software. Red shapes indicate upregulated proteins, and green shapes indicate downregulated proteins.

biological process. In addition, protein-protein interaction analysis using the IPA software also revealed marked alterations of APAF-1, RAD50 and TGF- $\beta 1$ in patients with PC.

As presented in Fig. 5 and Table IV, APAF-1 was significantly downregulated by 10 -fold in serum samples from patients with PC compared with the normal group. It has previously been demonstrated that APAF-1 is an essential and necessary component of apoptotic bodies in the intrinsic apoptotic pathway (16). APAF-1 serves an important role in the mitochondrial apoptotic pathway, primarily affecting the normal apoptosis of cells (17). Loss of heterozygosity and DNA methylation can inactivate APAF-1, which is a common phenomenon in numerous types of cancer in humans, including PC $(18,19)$. It has also been reported that when APAF-1 is inhibited in the pancreatic duct, it can result in the development of PC (17).

As an important component of the Mre11-Rad50-Nbs1 complex (20), RAD50 is primarily involved in maintaining chromosome stability. In the present study, RAD50 was increased by 2.2 -fold in serum samples from patients with PC compared with the normal group. A mutation analysis of 32 double-stranded DNA damage repair genes in breast cancer and $\mathrm{PC}$ revealed that RAD50 inactivation was more likely to promote the development of PC (21); however, high expression of RAD50 is conserved (22). It is not yet understood whether RAD50 protein upregulation in patients with PC is a protected molecular mechanism or whether the upregulation is maintained via negative feedback regulation; further research is required in order for the underlying mechanism to be elucidated.
TGF- $\beta$ plays an important role in cell cycle arrest, apoptosis, homeostasis, wound healing and immune regulation. In the case of cancer, TGF- $\beta$ plays a dual role in different situations, functioning as a tumor suppressor or oncogene in the early disease stages (23). TGF- $\beta$ has three isoforms, including TGF- $\beta 1$, TGF- $\beta 2$ and TGF- $\beta 3$; among them, TGF- $\beta 1$ is the most abundant in humans. The TGF- $\beta$ signaling pathway consists of several stages, starting with TGF- $\beta 1$ activation and release, followed by binding to three high affinity receptors (24). TGF- $\beta$ binds to TGF- $\beta$ R 1 and TGF- $\beta$ R2 receptors on the cell surface, forming dimeric-SMADs following activation. A previous study demonstrated that TGF- $\beta \mathrm{R} 2$ is one of the 16 most commonly mutated genes in PC (25). In multiple types of human cancer, the TGF- $\beta$ signaling pathway is activated (26). As presented in Table IV, TGF- $\beta 1$ was 1.67 -fold less expressed in serum samples from patients with PC compared with control values. Through IPA analysis of upstream regulatory genes of TGF- $\beta 1$, it was also revealed that significantly downregulated TGF- $\beta 1$ may be due to the suppression of hypoxia inducible factor 1 (HIF1) $\alpha$. According to a previous report, HIF1 $\alpha$ plays important roles in the growth, invasion and metastasis of PC (27). Significant changes in TGF- $\beta 1$ expression indicate that TGF- $\beta 1$ may be one of the diagnostic indices for PC.

The present study demonstrated APAF-1, RAD50 and TGF- $\beta 1$ should be considered candidate biomarkers for PC diagnosis. However, due to the limited sample size, further studies with larger sample sizes are required in order to confirm the identified differentially expressed proteins and validate their values in the diagnosis of PC. The results of the 
present study could aid in identifying future therapeutic drugs for the treatment of PC.

\section{Acknowledgements}

Not applicable.

\section{Funding}

The present study was supported by The Scientific and Technological Project in Shanxi (grant no. 100311099-3).

\section{Availability of data and materials}

All data generated or analyzed during the present study are included in this published article.

\section{Authors' contributions}

$\mathrm{KJ}$ and $\mathrm{XD}$ conceived and designed the study. KJ and $\mathrm{XZ}$ performed the experiments and data analyses. KJ wrote the manuscript. KJ and XD helped to revise the manuscript. XZ contributed to discussions and provided reagents/materials/analysis tools important for the completion of this work.

\section{Ethics approval and consent to participate}

All procedures performed in the present study that involved human participants were in accordance with the ethical standards of the institutional and/or national Ethics Committee and with the 1964 Helsinki declaration and its later amendments or comparable ethical standards. The present study was approved by the ethics committee of Shanxi Provincial Cancer Hospital (approval no. 201732). All the patients included in the present study provided written informed consent.

\section{Patient consent for publication}

Not applicable.

\section{Competing interests}

The authors declare that they have no competing interests.

\section{References}

1. American Cancer Society: Cancer Facts and Figs 2017. American Cancer Society, New York, NY, 2017.

2. Rahib L, Smith BD, Aizenberg R, Rosenzweig AB, Fleshman JM and Matrisian LM: Projecting cancer incidence and deaths to 2030: The unexpected burden of thyroid, liver, and pancreas cancers in the United States. Cancer Res 74: 2913-2921, 2014.

3. Ross PL, Huang YN, Marchese JN, Williamson B, Parker K, Hattan S, Khainovski N, Pillai S, Dey S, Daniels S, et al: Multiplexed protein quantitation in Saccharomyces cerevisiae using amine-reactive isobaric tagging reagents. Mol Cell Proteomics 3: 1154-1169, 2004

4. Blaney JM, Crawford G, Elder TR, Johnston G and Gavin AT: Hospital cancer deaths: Late diagnosis and missed opportunity. BMJ Support Palliat Care 1: 135-139, 2011.

5. Goh SK, Gold G, Christophi C and Muralidharan V: Serum carbohydrate antigen 19-9 in pancreatic adenocarcinoma: A mini review for surgeons. ANZ J Surg 87: 987-992, 2017.
6. Su SB, Qin SY, Chen W, Luo W and Jiang HX: Carbohydrate antigen 19-9 for differential diagnosis of pancreatic carcinoma and chronic pancreatitis. World J Gastroenterol 21: 4323-4333, 2015.

7. Chen J, Ge L, Liu A, Yuan Y, Ye J, Zhong J, Liu L and Chen X: Identification of pathways related to FAF1/H. Pylori-associated gastric carcinogenesis through an integrated approach based on iTRAQ quantification and literature review. J Proteomics 131: 163-176, 2016.

8. Wang X, Li Y, Xu G, Liu M, Xue L, Liu L, Hu S, Zhang Y, Nie Y, Liang S, et al: Mechanism study of peptide GMBP1 and its receptor GRP78 in modulating gastric cancer MDR by iTRAQ-based proteomic analysis. BMC Cancer 15: 358, 2015.

9. Martin-Bernabe A, Cortes R, Lehmann SG, Seve M, Cascante M and Bourgoin-Voillard S: Quantitative proteomic approach to understand metabolic adaptation in non-small cell lung cancer. J Proteome Res 13: 4695-4704, 2014.

10. Pan S, Brentnall TA and Chen R: Proteomics analysis of bodily fluids in pancreatic cancer. Proteomics 15: 2705-2715, 2015.

11. Pancreatic Surgery Group: Guidelines for Diagnosis and Treatment of Pancreatic Cancer (2014 Edition). Chin J Prac Surg 34: 1011-1017, 2014.

12. Amin MB, Edge S, Greene F, Brookland RK, Washington MK, Gershenwald JE, Compton CC, Hess KR, Sullivan DC, Jessup JM, Brierley JD, Gaspar LE, Schilsky RL, Balch CM, Winchester DP, Asare EA, Madera M, Gress DM and Meyer LR (eds): AJCC Cancer Staging Manual. 8th edition. Springer, New York, NY, 2016.

13. Kondo N, Murakami Y, Uemura K, Hayashidani Y, Sudo T, Hashimoto Y, Nakashima A, Sakabe R, Shigemoto N, Kato Y, et al: Prognostic impact of perioperative serum CA19-9 levels inpatients with resectable pancreatic cancer. Ann Surg Oncol 17: 2321-2329, 2010.

14. Luo G, Liu C, Guo M, Long J, Liu Z, Xiao Z, Jin K, Cheng H, Lu Y, Ni Q and Yu X: CA19-9-Low\&Lewis (+) pancreatic cancer: A unique subtype. Cancer Lett 385: 46-50, 2017.

15. Poruk KE, Gay DZ, Brown K, Mulvihill JD, Boucher KM, Scaife CL, Firpo MA and Mulvihill SJ: The clinical utility of CA19-9 in pancreatic adenocarcinoma: Diagnostic and prognostic updates. Curr Mol Med 13: 340-351, 2013.

16. Wu CC and Bratton SB: Regulation of the intrinsic apoptosis pathway by reactive oxygen species. Antioxid Redox Signal 19: 546-558, 2013.

17. Liu N, Sun YY, Zhang XW, Chen S, Wang Y, Zhang ZX, Song SW, Qiu GB and Fu WN: Oncogenic miR-23a in Pancreatic Ductal Adenocarcinogenesis Via Inhibiting APAF1. Dig Dis Sci 60: 2000-2008, 2015.

18. Umetani $\mathrm{N}$ and Hoon DS: Frequent LOH at chromosome 12q22-23 and Apaf-1 inactivation in glioblastoma. Brain Pathol 14: 224, 2004.

19. Fu WN, Bertoni F, Kelsey SM, McElwaine SM, Cotter FE, Newland AC and Jia L: Role of DNA methylation in the suppression of Apaf-1 protein in human leukaemia. Oncogene 22: 451-455, 2003.

20. Uziel T, Lerenthal Y, Moyal L, Andegeko Y, Mittelman L and Shiloh Y: Requirement of the MRN complex for ATM activation by DNA damage. EMBO J 22: 5612-5621, 2003.

21. Wang X, Szabo C, Qian C, Amadio PG, Thibodeau SN, Cerhan JR, Petersen GM, Liu W and Couch FJ: Mutational analysis of thirty-two double-strand DNA break repair genes in breast and pancreatic cancers. Cancer Res 68: 971-975, 2008.

22. Dzikiewicz-Krawczyk A: The importance of making ends meet: Mutations in genes and altered expression of proteins of the MRN complex and cancer. Mutat Res 659: 262-273, 2008.

23. Tian M and Schiemann WP: The TGF-beta paradox in human cancer: An update. Future Oncol 5: 259-271, 2009.

24. Bernabeu C, Lopez-Novoa JM and Quintanilla M: The emerging role of TGF-beta superfamily coreceptors in cancer. Biochim Biophys Acta 1792: 954-973, 2009.

25. Biankin AV, Waddell N, Kassahn KS, Gingras MC, Muthuswamy LB, Johns AL, Miller DK, Wilson PJ, Patch AM, $\mathrm{Wu}$ J, et al: Pancreatic cancer genomes reveal aberrations in axon guidance pathway genes. Nature 491: 399-405, 2012.

26. Wakefield LM and Hill CS: Beyond TGFbeta: Roles of other TGFbeta superfamily members in cancer. Nat Rev Cancer 13: 328-341, 2013.

27. Niu F, Li Y, Lai FF, Ni L, Ji M, Jin J, Yang HZ, Wang C, Zhang DM and Chen XG: LB-1 exerts antitumor activity in pancreatic cancer by inhibiting HIF- $1 \alpha$ and Stat 3 Signaling. J Cell Physiol 230: 2212-2223, 2015. 